\title{
BMJ Open Let's talk numbers: a qualitative study of community-dwelling US adults to understand the role of numeracy in the management of heart failure
}

\author{
Madeline R Sterling, ${ }^{1}$ Ariel F Silva, ${ }^{1}$ Laura Robbins, ${ }^{2}$ Savira K Dargar, ${ }^{1}$ \\ Marilyn M Schapira, ${ }^{3,4}$ Monika M Safford ${ }^{1}$
}

To cite: Sterling MR, Silva AF, Robbins L, et al. Let's talk numbers: a qualitative study of community-dwelling US adults to understand the role of numeracy in the management of heart failure. BMJ Open 2018;8:e023073. doi:10.1136/ bmjopen-2018-023073

- Prepublication history and additional material for this paper are available online. To view please visit the journal (http:// dx.doi.org/10.1136/bmjopen2018-023073).

This material was presented as a podium presentation at the Agency for Healthcare Research and Quality's (AHRQ) 23rd Annual National Research Service Award (NRSA) Research Trainees Conference, on 24 June 2017 in New Orleans, Louisiana, USA. This material was also presented as a podium presentation at the Weill Cornell Medicine's Primary Care Innovation Symposium, on 15 September 2017.

Received 21 March 2018

Revised 19 June 2018

Accepted 7 August 2018

Check for updates

(c) Author(s) (or their employer(s)) 2018. Re-use permitted under CC BY-NC. No commercial re-use. See rights and permissions. Published by BMJ.

For numbered affiliations see end of article.

Correspondence to Dr Madeline R Sterling; mrs9012@med.cornell.edu

\section{ABSTRACT}

Objective To examine the perspectives of adults with heart failure (HF) about numerical concepts integral to HF self-care.

Setting This qualitative study took place at an urban academic primary care practice.

Participants Thirty men and women aged 47-89years with a history of HF were recruited to participate. Eligibility criteria included: a history of $\mathrm{HF}$ ( $\geq 1$ year), seen at the clinic within the last year, and a HF hospitalisation within the last 6 months. Non-English speakers and those with severe cognitive impairment were excluded.

Methods In-depth semistructured interviews were conducted. Participants were interviewed about numeracy across three domains of HF self-care: (1) monitoring weight,(2) maintaining a diet low in salt and (3) monitoring blood pressure. Interviews were audio-taped, transcribed verbatim and analysed using grounded theory and word cloud techniques.

Results Five key themes reflecting participants' attitudes towards numerical concepts pertaining to weight, diet and blood pressure were identified: (1) Communication between healthcare providers and patients is a complex, multistage process; (2) Patients possess a wide range of knowledge and understanding; (3) Social and caregiver support is critical for the application of numerical concepts; (4) Prior health experiences shape outlook towards numerical concepts and instructions and (5) Fear serves as a barrier and a facilitator to carrying out HF selfcare tasks that involve numbers. The findings informed a theoretical framework of health numeracy in HF. Conclusion Effective communication of numerical concepts which pertain to HF self-care is highly variable. Many patients with HF lack basic understanding and numeracy skills required for adequate self-care. As such, patients rely on caregivers who may lack HF training. HF-specific training of caregivers and research that seeks to elucidate the intricacies of the patient-caregiver relationship in the context of health numeracy and HF selfcare are warranted.

\section{INTRODUCTION}

There are 1 million heart failure (HF) hospitalisations each year and $25 \%$ of patients admitted for $\mathrm{HF}$ are readmitted within

\section{Strengths and limitations of this study}

- This is the first study to examine the perspectives of patients with heart failure (HF) towards numerical concepts of HF self-care; the main results and theoretical framework which emerged add to the literature and have implications for future research and clinical care.

- A purposive sampling strategy was used to recruit a diverse group of patients, which is more methodologically rigorous than other sampling strategies.

- Interviews were thoroughly analysed using grounded theory.

- The study is limited in generalisability since it took place at one academic urban medical centre.

- The study only included English speaking patients with HF, which also limits the generalisability of the findings.

30 days. $^{1}{ }^{2}$ Part of this unplanned healthcare utilisation is thought to be preventable by improved HF self-care. ${ }^{3}$ Prior studies have found social and cognitive factors to be associated with HF self-care, including health literacy, ${ }^{4} \mathrm{HF}$ knowledge, ${ }^{5}{ }^{6}$ social support $^{78}$ and cognitive impairment. ${ }^{9}{ }^{10}$ Yet, little is known about health numeracy in the context of HF. ${ }^{1112}$

Health numeracy is the ability to access, understand and apply numerical data to health-related decisions. ${ }^{13}$ Although poor numeracy skills can coexist with low health literacy, numeracy and literacy measure different constructs and many adults tend to have worse quantitative skills. ${ }^{13-16}$ With respect to chronic diseases, low numeracy is associated with worse glycaemic control among adults with diabetes, ${ }^{14} 1718$ poor anticoagulation control among patients on warfarin, ${ }^{19}$ worse medication adherence ${ }^{20}$ among adults with HIV/AIDS and poor blood pressure control among adults with hypertension. ${ }^{21}$ 
Similar to these conditions, the management of HF requires numerical skill. Patients are expected to maintain a diet low in salt (often less than $2000 \mathrm{mg}$ /day), monitor their blood pressure and weigh themselves daily. However, despite the degree to which numerical skills are needed for adequate HF self-care, to date only two studies have examined numeracy in the context of HF and they have done so by investigating the association between numeracy and the risk of readmission among adults hospitalised for HF. ${ }^{1112}$ Although informative, the results of these studies were conflicting, and neither investigated the role of numeracy in the management of HF or from the patients' perspective. Herein, we addressed this gap by examining how numerical information is viewed and used among community-dwelling adults with HF.

\section{METHODS}

\section{Participant selection and study setting}

We conducted one-on-one semistructured interviews with 30 adults with a history of HF, from December 2016 to March 2017. Patients were recruited from a hospital-based ambulatory clinic in New York. To be considered eligible, patients must have had a diagnosis of HF for at least 1year, had an office visit at the clinic within the last year and must have been admitted to the hospital with a primary diagnosis of HF within the last 6 months. Non-English speakers, those with severe visual, hearing or cognitive impairment were excluded. The six-item screener ${ }^{22}$ was used to assess cognition. The electronic health record was used to identify patients with $\mathrm{HF}$ who met our eligibility criteria.

Among those who were eligible, purposive sampling ${ }^{23}$ was used to achieve a balanced sample with respect to gender, race/ethnicity and duration of HF (years), as prior qualitative studies have shown variation across these characteristics with respect to self-care. ${ }^{24}$ Purposive sampling is a technique widely used in qualitative research for the identification and selection of information-rich informants that cover the range of variation. ${ }^{23}$ Eligible patients were called by telephone to gauge their interested in participating. At their next clinic visit, they were approached by one author (AFS), who detailed the consent process.

Of the 72 patients who were eligible to participate, 32 refused and 4 were excluded for cognitive impairment (online supplementary figure 1). Of the 36 participants who provided written consent, six withdrew. Overall, our study included 30 participants.

\section{Data collection}

One author (MRS) with qualitative research experience conducted the in-person semistructured interviews with each participant which lasted up to $40 \mathrm{~min}$. Interviews were conducted using a standard interview guide, which included probes to elicit clarification and additional detail from participants. This approach is the most common in qualitative studies which seek to understand patients' perspectives on self-care in chronic diseases. ${ }^{25-27}$ The interview topic guide, which was informed by the numeracy literature (in other chronic diseases) as well as our clinical experience with patients with HF, allowed us to focus on numeracy in HF self-care, but also allowed for participant responses' to drive the direction and tone of the interview. The interview topic guide inquired about numeracy across three domains of HF self-care: (1) monitoring weight and fluid; (2) maintaining a low salt diet and (3) monitoring blood pressure (online supplementary appendix 1). Data saturation or the point at which no new themes emerged ${ }^{28}$ was achieved by the 17 th interview, however, additional interviews were conducted to maximise the robustness of the findings.

Participants completed a sociodemographic questionnaire following the interview. Medication use was ascertained through pill bottle review. The 10-item Centre for Epidemiological Studies Depression Scale was used to measure of depressive symptoms. ${ }^{29}$ To assess subjective numeracy skill, participants completed the Subjective Numeracy Scale (SNS), ${ }^{30}$ a validated 8-item instrument which measures numeracy on a scale of 6-48 with higher scores indicating higher numeracy skills.

Participants received a US $\$ 25.00$ gift card for their participation.

\section{Data analysis}

Interviews were audio-taped, professionally transcribed, and data were managed with ATLAS.ti Software. The data were analysed using grounded theory. ${ }^{31}{ }^{32}$ To ensure methodological rigour, a constant comparative approach was used at each stage of the analysis. ${ }^{33}{ }^{34}$ First, two investigators (MRS and AFS) independently reviewed and open coded the first five transcripts, each drafting a preliminary coding schema which totalled 551 codes. Codes were applied to segments of text, usually defined by one or more relevant concepts. A third investigator (LR) reviewed the first five transcripts and both code lists before consolidating the lists into a final codebook, which was composed of 77 unique codes. The investigators then reviewed the transcripts a second time, coding the data using the uniform codebook, which was subsequently applied to the remaining transcripts. During this process, the two coders met to revise the codebook, removing some codes while adding others. Once all transcripts were coded, the three investigators then compared common codes using dimensions and properties and consolidated them into 13 categories by consensus. The categories were then consolidated into five unifying themes, which a fourth investigator reviewed (MMS). Quotations from each theme were anonymised and selected for presentation.

\section{Theoretical framework}

Since little is known about numeracy in the context of $\mathrm{HF}$, and since existing frameworks did not incorporate the scope of the themes that emerged herein, ${ }^{35-37}$ a new theoretical framework was generated from the analysis. To develop this framework, we first created a visualisation of all of the initial codes which emerged directly from the interview transcripts using word cloud software in ATLAS.ti (online supplementary figure 2). In this word cloud, the size 


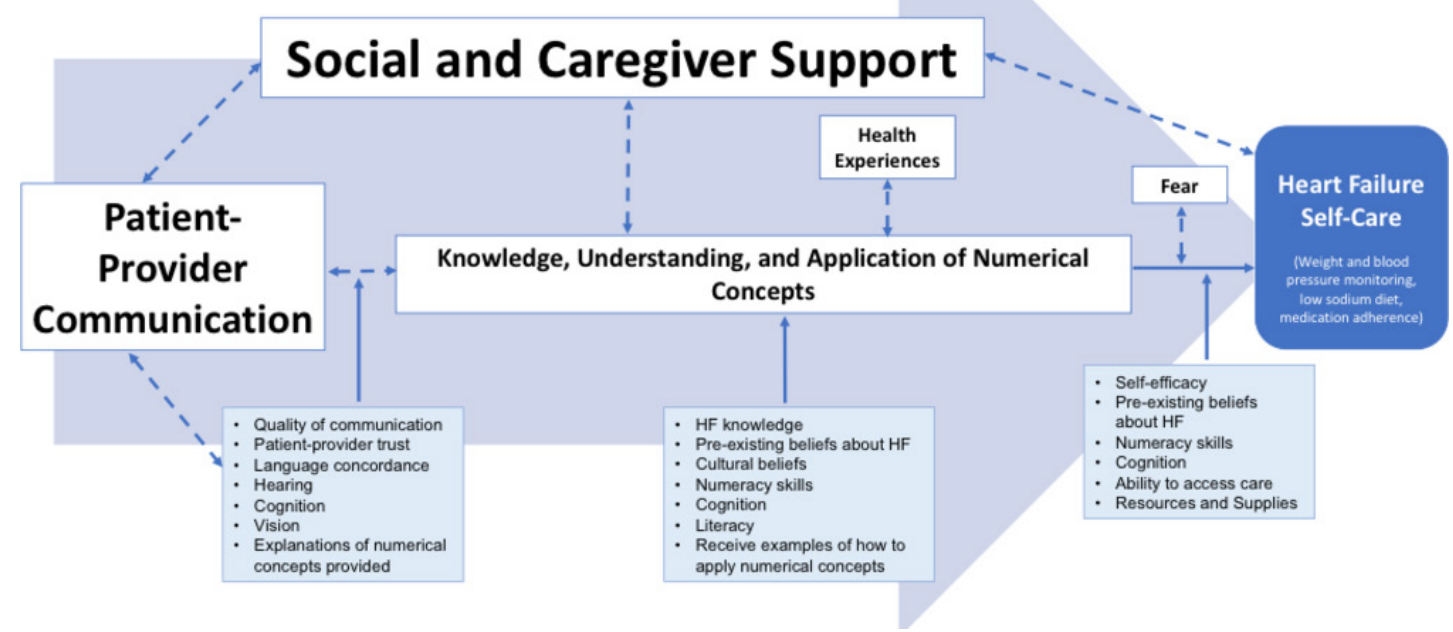

Figure 1 Theoretical framework of factors influencing effective use of numbers in heart failure (HF) self-care. The theoretical framework is a summation of the thematic content derived from grounded theory, along with features of the word cloud. As shown by their size, social and caregiver support and patient-provider communication emerged as the two most dominant themes. One overarching arrow (left to right), as well as smaller ones, detail the relationship between themes, categories and prominent codes. Solid arrows represent unidirectional relationships, whereas dashed bi-directional arrows represent bidirectional relationships. Input from study participants was incorporated into this final conceptual framework.

of a code represented the frequency in which it appeared; the larger the size, the more often the code appeared. ${ }^{38}$ This enabled us to get a preliminary sense of what concepts were discussed most often, by the participants. Our initial framework retained the properties of the word cloud, but also incorporated the categories and themes which emerged during the analytic process (online supplementary figure 3). After feedback from study participants and health services researchers, we developed a more unified theoretical framework (figure 1).

\section{Quality assurance}

The study adhered to the Consolidated Criteria for Reporting Qualitative research. ${ }^{39}$

\section{Patient and public involvement}

Additionally, to ensure that our study had the ability to investigate the perspective of patients with HF on health numeracy, the semistructured interview guide and the postinterview survey were piloted for ease and comprehensibility with five patients with $\mathrm{HF}$ who were not included in the final study. At the conclusion of the study, the findings were shared with the study participants. Findings were also disseminated to the scientific community at two research conferences in 2017.

\section{RESULTS}

\section{Characteristics of study population}

The 30 participants were mean age of 67years (SD 10), 17 $(57 \%)$ were female, $7(23 \%)$ were white, 15 (50\%) were black, $6(20 \%)$ were Hispanic and $2(7 \%)$ were Asian/Pacific Islander (table 1$)$. Twenty-one $(70 \%)$ had at least a high school education and 12 (40\%) had Medicare or Medicaid. On average, participants had HF for 11 years (SD 7.8) and 22 $(73 \%)$ were considered to have New York Heart Association classes 2 and 3. The mean SNS was 27 (SD 10.3).

\section{Major themes}

Five key themes emerged from our study, which are subsequently described and illustrated with anonymised quotes.

Theme 1: communication between healthcare providers and patients is a complex, multistage process

Participants described the process of receiving numerical information about HF self-care to be a highly variable. one. While some patients with HF had received information and instructions about weighing themselves, following a low salt diet and monitoring their blood pressure during the course of their disease, others had not. This variation in communication is represented by the following two quotations:

Every doctor at the office and in the hospital told me I need to follow a low salt diet.

This is the first time I've ever heard that I'm supposed to weigh myself at home. Should I be doing that?

Among those who did receive this information, few reported receiving accompanying explanations or reallife examples of how to apply numerical concepts and instructions, as shown here:

Yeah, I take the 40-dose of the water pill every day. But, no one explained to me why I take it, or why 40. $2000 \mathrm{mg}$ - what does that even mean? What does that number represent? Nobody has explained that to me. 
Table 1 Characteristics of the study population

\begin{tabular}{lc}
\hline Participant characteristics & All $(\mathbf{n}=\mathbf{3 0})$ \\
\hline Age, years (mean (SD)) & $67(10)$ \\
Gender &
\end{tabular}

\begin{tabular}{|c|c|}
\hline Female, N (\%) & $17(57)$ \\
\hline \multicolumn{2}{|l|}{ Race } \\
\hline White, N (\%) & $7(23)$ \\
\hline Black, N (\%) & $15(50)$ \\
\hline Hispanic, N (\%) & $6(20)$ \\
\hline Asian/Pacific islander, $\mathrm{N}(\%)$ & $2(7)$ \\
\hline \multicolumn{2}{|l|}{ Educational degree } \\
\hline No degree, N (\%) & $3(10)$ \\
\hline Some High School (HS), N (\%) & $6(20)$ \\
\hline $\begin{array}{l}\text { General Education Diploma (GED) or HS } \\
\text { completed, N (\%) }\end{array}$ & $6(20)$ \\
\hline Some college, N (\%) & $8(27)$ \\
\hline Four-year college degree, $\mathrm{N}(\%)$ & $3(10)$ \\
\hline Graduate degree, N (\%) & $4(13)$ \\
\hline \multicolumn{2}{|l|}{ Insurance type } \\
\hline None, N (\%) & $5(21)$ \\
\hline Private, N (\%) & $7(29)$ \\
\hline Medicare, N (\%) & $5(21)$ \\
\hline Medicaid, N (\%) & $6(25)$ \\
\hline Medicare and Medicaid, N (\%) & $1(6)$ \\
\hline \multicolumn{2}{|l|}{ NYHA class, $N(\%)$} \\
\hline 1 & $8(27)$ \\
\hline 2 & $11(37)$ \\
\hline 3 & $11(37)$ \\
\hline No of years with HF diagnosis, years (mean (SD)) & $10.9(7.8)$ \\
\hline \multicolumn{2}{|l|}{ No of medications taking for $\mathrm{HF}$} \\
\hline Do not know, N (\%) & $2(7)$ \\
\hline $1-5, \mathrm{~N}(\%)$ & $25(83 \%)$ \\
\hline $6-10, N(\%)$ & $3(10)$ \\
\hline$>10, \mathrm{~N}(\%)$ & 0 \\
\hline \multicolumn{2}{|l|}{ No of medications taking overall } \\
\hline Do not know, N (\%) & 0 \\
\hline $1-5, N(\%)$ & $3(10)$ \\
\hline $6-10, N(\%)$ & $19(63)$ \\
\hline$>10, \mathrm{~N}(\%)$ & $8(27)$ \\
\hline \multicolumn{2}{|l|}{ Depressed symptoms } \\
\hline CES-D-10, mean (SD) & $12.3(5.3)$ \\
\hline \multicolumn{2}{|l|}{ Subjective numeracy } \\
\hline SNS-8, mean (SD) & 27 (10.3) \\
\hline
\end{tabular}

The 10-item Centre for Epidemiological Studies Depression Scale (CES-D-10) was used to measure of depressive symptoms, with higher scores indicating more depressive symptoms. The Subjective Numeracy Scale (SNS-8) assessed patients' numeracy. The SNS-8 is a validated 8-item instrument which measures numeracy on a scale of 6-48 with higher scores indicating higher numeracy skills.

HF, heart failure; NYHA, New York Heart Association.

Participants revealed that common barriers to communicating about these topics with providers in the clinic and the hospital included memory loss and hearing loss and visual impairment:
I'm not sure if anyone gave me instructions about a $2000 \mathrm{mg}$ salt diet. I forget things. Maybe they did and I don't remember?

I'm embarrassed when I can't hear the doctor. My hearing aids broke a while back.

In addition to not having hearing aids, several participants conveyed that they go to the doctor's office without their reading glasses.

Notably, many participants spoke of non-physicians, particularly nurse practitioners, dieticians and pharmacists, as critical to the communication and understanding of numerical information and instructions in HF. However, when they received abnormal numerical results, many preferred to speak directly with physicians:

When my blood pressure is very high, I write it down and tell my doctor at my next appointment.

Some went directly to the emergency department when they saw abnormal values at home, rather than first calling their physician:

When my blood pressure is out of control, I go straight to the hospital. Nothin' my doctor can do when I'm home.

Finally, participants spoke about the importance of the patient-provider relationship in communication. Specifically, many felt that this relationship affected their willingness to ask physicians questions about numerical concepts. Here, one participant expresses comfort and trust:

I always ask my doctor questions. Especially if I see a funny number on my pressure cuff. He's a wonderful man-easy to talk to.

On the contrary, distrust, lack of provider continuity and fear of being judged by the provider were barriers to asking questions:

He told me about weighing myself.... It confused me, but I didn't wanna seem dumb, so I never asked him to explain it again.

Theme 2: patients possess a wide range of knowledge and understanding

While some participants understood the reason for monitoring weight, blood pressure and salt intake, others struggled to grasp these concepts:

I understand why my doctor told me to weigh myself. He doesn't want me to gain weight because it's a sign of water build up.

I still don't understand blood pressure. The doctors have tried to explain it, but it's a concept I just can't handle.

Among those who expressed an understanding of numerical concepts associated with HF self-care, many participants struggled to apply them correctly. In fact, 
when given scenarios about abnormal values, many failed to interpret them and answer correctly:

Last month my weight went up on the scale and my legs got really swollen. But I didn't do nothing. I waited until the shortness of breath came.

While some participants were aware of their shortcomings, others were not. Instead, they were confident in their incorrect knowledge and actions. The following two quotations represent the 'strong and wrong' patient:

I hardly ever eat salt. Take yesterday-I had two pancakes for breakfast, a can of sardines for lunch, and then soup for dinner.

My blood pressure is usually $170 / 100$. That's bad because the 100 is high—the bottom number is the important one.

Overall, participants' statements suggest that there is a mismatch between self-perceived and actual ability and that they struggle to apply concepts correctly in their day-to-day lives.

Finally, participants cited a lack of financial resources as a main barrier to monitoring blood pressure and eating healthy:

I'm on meals on wheels. I eat what they give me.

In addition, chronic pain was cited as a barrier to grocery shopping and standing on a scale during weight measurement.

Theme 3: social and caregiver support is critical for the application of numerical concepts

The role of social and caregiver support was prominent throughout the interviews. The majority of participants reported that someone in their life helped them manage their HF. Family caregivers (spouses, grown children and relatives) and paid caregivers (home health aides, home attendants and care managers), provided participants with emotional and functional support. In addition to helping with weight monitoring, diet and blood pressure control, caregivers assisted with grocery shopping, meal preparation and transportation.

Participants frequently asked caregivers to interpret and explain numerical concepts at home, as illustrated here:

When we leave the office, I ask my daughter what the doctor meant with those blood pressure numbers.

I get so many questions in my head when I get on the bus, so I call my care manager. She's good at explaining.

This heavy reliance on caregivers had both positive and negative effects on patients' ability to apply numerical concepts and information correctly, as demonstrated by the following two quotations:

My wife looks at every single label and adds up what I can eat in terms of salt. She comes to every visit and hounds the doctor with so many questions.
I don't know if I have a low-salt diet. Whatever my health aide cooks me, is what I eat.

Finally, while being described as critical to their ability to engage in self-care, caregivers were not always in the room them and the doctor. Yet, despite not being present, participants recounted that caregivers are often responsible for calling the physician for further clarification of numerical instructions.

\section{Theme 4: prior health experiences shape outlook towards} numerical concepts and instructions

For many participants, attitudes and pre-existing beliefs towards HF informed their outlook towards numerical concepts associated with HF. Their ability to process and carry out numerical instructions was affected by duration of $\mathrm{HF}$ and their ability to adjust to the diagnosis:

I didn't like getting all of them directions at first. It depressed me, 'weigh yourself and drink only this amount.' But then I came to terms with it.

For some, the longer they had HF, the better they were at HF self-care, while for others, a longer duration of illness led to less engagement. Some participants spoke about relying on their symptoms to signal an acute worsening of their HF, rather than weighing themselves, which is a view is represented here:

Look I've had this disease for years now. I don't needa' do any of this. I know when a flair up is coming.

In addition, personal and cultural beliefs shaped behaviour.

People at my Church get sick with this heart failure.

They told me I better stay on top of this stuff, so I do.

In addition to their attitudes towards HF, experience with other chronic diseases and the healthcare system seemed to affect their comfort with numeracy skills integral to HF self-care.

For example, participants on dialysis, those taking warfarin and those with insulin-dependent diabetes seemed relatively comfortable with numerical concepts and instructions pertaining to HF:

Following a low salt diet is pretty easy. I've been on Coumadin for years and I learned to limit foods because of the ' $\mathrm{K}$ ' issue.

Theme 5: fear serves as a barrier and a facilitator to carrying out $\mathrm{HF}$ self-care tasks that involve numbers

Interviews revealed that fear played a dual role. Some participants expressed fear of abnormal results, which hindered their willingness to carry out numeric instructions:

I don't take my blood pressure because it's better if I don't know my numbers. If I know, I'll worry sick.

For others, however, the fear of death served as a facilitator in carrying out HF self-care tasks: 
I follow all of these instructions. Always. I want to be here for my children.

In addition to death, the fear of shortness of breath, being hospitalised, readmitted and dying served as facilitators in carrying out self-care tasks at home.

I really try and stay away from salt. Not being able to breathe, is a nasty symptom.

\section{Theoretical framework}

The theoretical framework that emerged from these results elucidates the role of numeracy in the context of HF self-care from the patients' perspective (figure 1). Here, the main themes that emerged from our study are in white boxes and are scaled to the size in which they affected HF self-care, from the patients' perspective. The size of the themes reflects both the degree to which they appeared in the word cloud, but also from the interpretation of the quotations in the interview transcripts. As such, social and caregiver support and patient-provider communication appear the largest in size, since these themes were most dominant in influencing outcomes, from the patients' perspectives. Blue boxes contain factors or subthemes, which could mediate the relationship between themes. One overarching arrow (left to right), as well as smaller arrows, detail the relationship between the themes and the other factors identified.

\section{DISCUSSION}

To our knowledge, this is the first study to evaluate the role of numeracy in the context of HF from the patients' perspective. Our findings add to the literature in several key ways. First, we found that among a socioeconomically and racially diverse group of patients with HF, many lacked basic numerical understanding and numeracy skills required for adequate self-care. Second, we found that the communication of numerical concepts between healthcare providers and patients is a complex and highly variable process. Third, participants relied heavily on caregivers to help them understand and carry out self-care tasks which required numeracy skills. Finally, as depicted in our theoretical framework, we found that while patient numeracy skills are important, they may not be as critical as patient-provider communication and caregiver support are to understanding and applying numerical concepts pertaining to HF self-care.

Like other studies that found that patients with HF struggle with HF self-care, ${ }^{40} 41$ our findings suggest that patients have difficulty integrating and applying numerical concepts and instructions home. For example, while many participants reported receiving information about a low sodium diet, few were able to correctly navigate reallife scenarios that asked them to calculate the sodium content in a meal. This deficit is consistent with a study by Rothman et al, which highlighted patient shortfalls with nutrition label comprehension. ${ }^{42}$ In addition, many participants struggled with understanding the implications of abnormal blood pressure values. This mismatch was also seen with SNS scores; many of the participants who rated themselves as above average with respect to numeracy, were unable to correctly apply numerical concepts during the in-person interview. Notably, some participants were unaware that they possessed incorrect information. While others have shown that perceived numerical abilities differ from actual abilities, ${ }^{43}$ ours is the first to report on this in HF, which has important implications for hospital discharge planning and clinic visits.

While our goal was to examine numeracy from the perspective of patients with HF, many of the patients we interviewed relied heavily on family and paid caregivers to understand and perform HF self-care tasks that required numeracy skills. Notably, this finding differs from the existing body of numeracy literature in other chronic diseases, which has focused on individual patient numeracy. ${ }^{14-16} 1921$ Plausible explanations include that HF requires a high degree of self-care, they are frequently hospitalised, and they tend to be older, have multiple functional and cognitive deficits, all of which may lead them needing more help with respect to numerical tasks. ${ }^{45} 46$ This may have both positive and negative implications though, as prior studies suggest that relying on caregivers has inconsistent effects on patients' disease management. ${ }^{4748}$ The numeracy skill level of caregivers in HF has not been investigated and is potentially warranted.

In addition, we found that the communication of numerical concepts and instructions between providers and patients is a multistage process, which can go awry at several points. As depicted by our theoretical framework, receiving numerical information requires that providers offer it and that patients are able to hear, see and cognitively process the information. Recent data suggest that in the USA, $75 \%$ of older adults with HF have mild or greater hearing loss, ${ }^{49}$ one out of four adults with HF has trouble seeing up close ${ }^{50}$ and many are cognitively impaired. ${ }^{51}$ In addition to these cognitive and sensory deficits, we found that comprehension and application of numerical concepts more often than not, required explanations and real-life examples, as well as adequate time for questions. Addressing these elements will require interventions that can overcome the constraints of contemporary office visits, which are often too short to allow this kind of interaction. Given the degree to which participants relied on non-physicians for information, it is likely that a multidisciplinary team of healthcare providers could address some of these needs.

Interestingly, we found that when participants received an abnormal numerical result at home, such as a high blood pressure reading, they preferred to discuss it with their physician in the office, ask caregivers for help or go directly to the emergency department, rather than call their physician. There are a few possible reasons for why this may be. First, barriers in the healthcare system may discourage them from calling. Second, the 
patient-provider relationship may be an important determinant, since we found that those who called their physician reported feeling 'close' to them. Third, patient characteristics like hearing loss and language barriers may deter phone communication. Of note, none of our participants reported having telehealth devices which are known to transmit numerical results to the physician directly. It may be prudent for interventions to design flexible decision support tools which allow for varying knowledge, support in the home and practice characteristics.

Finally, as depicted by our theoretical framework, we found that several patient-level factors influenced how numerical information was perceived and acted on. Participants who had other conditions which required them to manipulate numbers and those who feared negative consequences of not following numerical instructions were more willing to carry out more numerically burdensome HF self-care tasks. Additionally, as shown in our framework, self-efficacy, financial resources (owning a scale and being able to buy food low in salt) and the ability to access care were factors that affected this willingness to engage. Thus, in addition to providers being aware of patients' outlook, beliefs and attitudes, interventions which could address some of these more modifiable factors ought to be examined.

\section{Strengths and limitations}

Our study's strengths include that it is the first qualitative study to examine numeracy in the context of HF. We used a purposive sampling strategy to recruit a diverse group of patients to seek a range of perspectives across gender, race/ethnicity and chronicity of HF. Finally, we develop a novel theoretical framework from our findings which can guide future research and interventions on numeracy in HF. Despite purposive sampling, however, the study is limited in generalisability due to recruitment from a single clinical cite. Our focus was the patients' perspective, but given our findings, future studies should examine the perspectives of HF patients' caregivers on numeracy. Another limitation is that we did not formally assess participants' health literacy, since it is thought to be a similar but distinct concept from numeracy and a wealth of research has already focused on literacy in the context of HF. However, future studies may consider doing so since health literacy is likely to affect many aspects of HF self-care. Finally, we excluded non-English speakers, who may experience numerical concepts differently than patients discussed here. ${ }^{52}$

\section{CONCLUSION}

Overall, our findings suggest that the communication of numerical concepts and instructions between providers and patients with HF is a complex, multistage process and the numerical information which is transmitted to patients may be highly variable. In addition, receiving, understanding and applying numerical concepts integral to HF self-care is challenging for many adults with HF.
Perhaps owing to this, we found that many patients with HF rely heavily on caregivers to perform numerical tasks and interpret numerical results. Since our study focused on patients with HF, future studies ought to assess the numeracy skills of caregivers relative to these demands. As depicted by our theoretical framework, patient-provider communication and HF-specific training of caregivers may be important influences on successful HF self-care, rather than interventions aimed at individual patient numeracy alone. In addition, several patient-level factors, such as sensory impairments, prior experiences with other chronic diseases, access to resources and the quality of patient-provider relationship, have the ability to affect the degree to which numerical concepts are understood and applied correctly. Healthcare providers ought to be mindful of these issues when counselling patients on numerical tasks, as a one-size fits all approach is not likely to successful.

\section{Author affiliations}

${ }^{1}$ Division of General Internal Medicine, Department of Medicine, Weill Cornell Medical College, New York City, New York, USA

${ }^{2}$ Education and Academic Affairs, Hospital for Special Surgery, New York City, New York, USA

${ }^{3}$ Department of Medicine, Perelman School of Medicine, University of Pennsylvania, Philadelphia, Pennsylvania, USA

${ }^{4}$ Center for Health Equity Research and Promotion, Crescenz VA Medical Center, Philadelphia, Pennsylvania, USA

Acknowledgements We would like to thank all of the patients at Weill Cornell Internal Medicine Associates who gave their time and offered us their valuable insights. We would also like to thank Fred Pelzman and Judy Tung for their clinical support; Mary Charlson and Carol Mancuso for their research guidance; Travis Gossey for assistance with the electronic medical record and Jim Hollenberg for creating a secure web-site on ClinvestiGator for data entry.

Contributors Concept and design of the Study: MRS, MMSa, MMSc and SKD. Acquisition of data and analysis: MRS, AFS, SKD, LR and MMSa. Drafting of the manuscript: MRS. Critical revision of the manuscript: MRS, MMSc and MMSa. Final approval of the manuscript: MRS, AFS, MMSc, LR, MMSa and SKD.

Funding MRS was supported by T32HS000066 from the Agency for Healthcare Research and Quality during the conduct and submission of this study.

Disclaimer The content is solely the responsibility of the authors and does not necessarily represent the official views of the Agency for Healthcare Research and Quality.

Competing interests MMSa receives salary support for investigator-initiated research from Amgen.

Patient consent Obtained.

Ethics approval The study was approved by the Institutional Review Board of the Weill Cornell Medical College.

Provenance and peer review Not commissioned; externally peer reviewed.

Data sharing statement Due to the qualitative nature of this study, the data are written transcripts of patient interviews. Although participant information is deidentified, some made references to their experiences with individual physicians, healthcare providers and hospitals during the interviews, thus, we prefer to not make these transcripts publically available.

Open access This is an open access article distributed in accordance with the Creative Commons Attribution Non Commercial (CC BY-NC 4.0) license, which permits others to distribute, remix, adapt, build upon this work non-commercially, and license their derivative works on different terms, provided the original work is properly cited, appropriate credit is given, any changes made indicated, and the use is non-commercial. See: http:// creativecommons.org/licenses/by-nc/4.0/. 


\section{REFERENCES}

1. Jencks SF, Williams MV, Coleman EA. Rehospitalizations among patients in the Medicare fee-for-service program. N Engl J Med 2009;360:1418-28.

2. Lloyd-Jones D, Adams RJ, Brown TM, et al. Heart disease and stroke statistics-2010 update: a report from the American Heart Association. Circulation 2010;121:e46-215.

3. Riegel B, Moser DK, Anker SD, et al. State of the science: promoting self-care in persons with heart failure: a scientific statement from the American Heart Association. Circulation 2009;120:1141-63.

4. Cajita MI, Cajita TR, Han HR, et al. Health literacy and heart failure: a systematic review. J Cardiovasc Nurs 2016;31:121-30.

5. Dennison CR, McEntee ML, Samuel L, et al. Adequate health literacy is associated with higher heart failure knowledge and self-care confidence in hospitalized patients. J Cardiovasc Nurs 2011;26:359-67.

6. Macabasco-O'Connell A, DeWalt DA, Broucksou KA, et al. Relationship between literacy, knowledge, self-care behaviors, and heart failure-related quality of life among patients with heart failure. $J$ Gen Intern Med 2011;26:979-86.

7. Khaledi GH, Mostafavi F, Eslami AA, et al. Evaluation of the effect of perceived social support on promoting self-care behaviors of heart failure patients referred to the cardiovascular research center of Isfahan. Iran Red Crescent Med J 2015;17:e22525.

8. Shahriari M, Ahmadi M, Babaee S, et al. Effects of a family support program on self-care behaviors in patients with congestive heart failure. Iran J Nurs Midwifery Res 2013;18:152-7.

9. Davis KK, Himmelfarb CR, Szanton SL, et al. Predictors of heart failure self-care in patients who screened positive for mild cognitive impairment. J Cardiovasc Nurs 2015;30:152-60.

10. Harkness K, Heckman GA, Akhtar-Danesh N, et al. Cognitive function and self-care management in older patients with heart failure. Eur $J$ Cardiovasc Nurs 2014;13:277-84.

11. McNaughton CD, Collins SP, Kripalani S, et al. Low numeracy is associated with increased odds of 30-day emergency department or hospital recidivism for patients with acute heart failure. Circ Heart Fail 2013;6:40-6.

12. Sterling MR, Safford MM, Goggins K, et al. Numeracy, health literacy, cognition, and 30-day readmissions among patients with heart failure. J Hosp Med 2018;13.

13. Rothman RL, Montori VM, Cherrington A, et al. Perspective: the role of numeracy in health care. J Health Commun 2008;13:583-95.

14. Cavanaugh $\mathrm{K}$, Huizinga MM, Wallston KA, et al. Association of numeracy and diabetes control. Ann Intern Med 2008;148:737-46.

15. Abdel-Kader K, Dew MA, Bhatnagar M, et al. Numeracy skills in CKD: correlates and outcomes. Clin J Am Soc Nephrol 2010;5:1566-73.

16. Schwartz LM, Woloshin S, Black WC, et al. The role of numeracy in understanding the benefit of screening mammography. Ann Intern Med 1997;127:966-72.

17. Bowen ME, Cavanaugh KL, Wolff K, et al. Numeracy and dietary intake in patients with type 2 diabetes. Diabetes Educ 2013;39:240-7.

18. Osborn CY, Cavanaugh $\mathrm{K}$, Wallston KA, et al. Diabetes numeracy: an overlooked factor in understanding racial disparities in glycemic control. Diabetes Care 2009;32:1614-9.

19. Estrada CA, Martin-Hryniewicz M, Peek BT, et al. Literacy and numeracy skills and anticoagulation control. Am J Med Sci 2004;328:88-93.

20. Moore JO, Boyer EW, Safren S, et al. Designing interventions to overcome poor numeracy and improve medication adherence in chronic illness, including HIV/AIDS. J Med Toxicol 2011;7:133-8.

21. Rao VN, Sheridan SL, Tuttle LA, et al. The effect of numeracy level on completeness of home blood pressure monitoring. J Clin Hypertens 2015;17:39-45

22. Callahan CM, Unverzagt FW, Hui SL, et al. Six-item screener to identify cognitive impairment among potential subjects for clinical research. Med Care 2002;40:771-81.

23. Palinkas LA, Horwitz SM, Green CA, et al. Purposeful sampling for qualitative data collection and analysis in mixed method implementation research. Adm Policy Ment Health 2015;42:533-44.

24. Wisdom JP, Cavaleri MA, Onwuegbuzie AJ, et al. Methodological reporting in qualitative, quantitative, and mixed methods health services research articles. Health Serv Res 2012;47:721-45.

25. Stuckey $\mathrm{H}$. Three types of interviews: qualitative research methods in social health. J Soc Health Diabetes 2013;1:56-9.
26. Strauss $\mathrm{Ca}, 2015$. Basics of qualitative research. https://us.sagepub. com/en-us/nam/basics-of-qualitative-research/book235578

27. Glaser BG, Anselm L. Strauss, and elizabeth strutzel. The discovery of grounded theory; strategies for qualitative research.

28. Guest G, Bunce A, Johnson L. How many interviews are enough? an experiment with data saturation and variability. Field Methods 2006;18:59-82.

29. Andresen EM, Malmgren JA, Carter WB, et al. Screening for depression in well older adults: evaluation of a short form of the CES-D (Center for Epidemiologic Studies Depression Scale). Am J Prev Med 1994;10:77-84.

30. Fagerlin A, Zikmund-Fisher BJ, Ubel PA, et al. Measuring numeracy without a math test: development of the Subjective Numeracy Scale. Med Decis Making 2007;27:672-80.

31. Foley G, Timonen V. Using grounded theory method to capture and analyze health care experiences. Health Serv Res 2015;50:1195-210.

32. Merriam SB. Qualitative research: a guide to design and implementation. San Francisco, California: Jossey-Bass, 2009.

33. Eaves YD. A synthesis technique for grounded theory data analysis. J Adv Nurs 2001;35:654-63.

34. Charmaz K. Constructing grounded theory: a practical guide through qualitative analysis. Thousand Oaks: Sage Publications Inc, 2006.

35. Schapira MM, Fletcher KE, Gilligan MA, et al. A framework for health numeracy: how patients use quantitative skills in health care. $J$ Health Commun 2008;13:501-17.

36. Lipkus IM, Peters E. Understanding the role of numeracy in health: proposed theoretical framework and practical insights. Health Educ Behav 2009;36:1065-81.

37. Ancker JS, Kaufman D. Rethinking health numeracy: a multidisciplinary literature review. J Am Med Inform Assoc 2007;14:713-21.

38. McNaught CaL P. Using wordle as a supplementary research tool. The Qualitative Report 2010;15:630-43.

39. Tong A, Sainsbury P, Craig J. Consolidated criteria for reporting qualitative research (COREQ): a 32-item checklist for interviews and focus groups. Int J Qual Health Care 2007;19:349-57.

40. Spaling MA, Currie K, Strachan PH, et al. Improving support for heart failure patients: a systematic review to understand patients perspectives on self-care. J Adv Nurs 2015;71:2478-89.

41. Harkness K, Spaling MA, Currie K, et al. A systematic review of patient heart failure self-care strategies. J Cardiovasc Nurs 2015;30:121-35.

42. Rothman RL, Housam R, Weiss $\mathrm{H}$, et al. Patient understanding of food labels: the role of literacy and numeracy. Am J Prev Med 2006;31:391-8.

43. Dolan JG, Cherkasky OA, Li Q, et al. Should health numeracy be assessed objectively or subjectively? Med Decis Making 2016;36.

44. Ciampa PJ, Osborn CY, Peterson NB, et al. Patient numeracy, perceptions of provider communication, and colorectal cancer screening utilization. J Health Commun 2010;15 Suppl 3:157-68.

45. Delazer M, Kemmler G, Benke T. Health numeracy and cognitive decline in advanced age. Neuropsychol Dev Cogn B Aging Neuropsychol Cogn 2013;20:639-59.

46. Pertl MT, Benke T, Zamarian L, et al. Do patients with mild cognitive impairment understand numerical health information? J Alzheimers Dis 2014;40:531-40.

47. Rosland AM, Heisler M, Choi HJ, et al. Family influences on selfmanagement among functionally independent adults with diabetes or heart failure: do family members hinder as much as they help? Chronic IIIn 2010;6:22-33.

48. Strachan PH, Currie K, Harkness K, et al. Context matters in heart failure self-care: a qualitative systematic review. J Card Fail 2014;20:448-55

49. Sterling MR, Lin FR, Jannat-Khah DP, et al. Hearing loss among older adults with heart failure in the United States: data from the national health and nutrition examination survey. JAMA Otolaryngol Head Neck Surg 2018;144:273-5.

50. Sterling MR, Jannat-Khah D, Vitale S, et al. Can your patients with heart failure see? The prevalence of visual impairment among adults with heart failure. J Gen Intern Med 2018;33:605-7.

51. Dardiotis E, Giamouzis G, Mastrogiannis D, et al. Cognitive impairment in heart failure. Cardiol Res Pract 2012;2012:1-9.

52. Schapira MM, Fletcher KE, Ganschow PS, et al. The meaning of numbers in health: exploring health numeracy in a Mexican-American population. J Gen Intern Med 2011;26:705-11. 